\title{
The efficiency of mechanisms driving Subauroral Polarization Streams (SAPS)
}

\author{
H. Wang ${ }^{1}$ and H. Lühr ${ }^{2}$ \\ ${ }^{1}$ Dept. of Space Physics, School of Electronic Information, Wuhan University, Wuhan 430079, China \\ ${ }^{2}$ Helmholtz Centre Potsdam-GFZ, German Research Center for Geosciences, 14473 Potsdam, Germany
}

Received: 5 March 2011 - Revised: 28 June 2011 - Accepted: 30 June 2011 - Published: 20 July 2011

\begin{abstract}
We have investigated the seasonal and diurnal variation of SAPS (Subauroral Polarization Streams) occurrence based on 3663 SAPS events identified in DMSP ion drift observations in the Northern Hemisphere during July 2001 and June 2003. Their relationships with high latitude convection electric field, substorm, and ionospheric conductivity have been addressed. SAPS occurrences show a clear seasonal and diurnal variation with the occurrence rates varying by a factor of 5 . It is found that the convection electric field might play a dominant role in association with SAPS occurrence. Peak convection electric fields mark the occurrence maximum of SAPS. Substorm might play a secondary role related to SAPS occurrence. It account for the secondary maximum in SAPS occurrence rate during December solstice. Our work demonstrates that the substorm induced electric field can develop SAPS during relatively low global convection. Somewhat low fluxtube-integrated conductivity is favorable for SAPS to develop. Another topic is the temporal relationship between SAPS and substorm phases. SAPS can occur at substorm onset, substorm expansion and recovery phases. Most probably SAPS tend to occur $60 \mathrm{~min} / 45 \mathrm{~min}$ after substorm onset during quiet/more disturbed geomagnetic activity, respectively. This indicates that enhanced global convection helps SAPS to develop quicker during substorms. The peak plasma velocity of SAPS is increased on average only by $5-10 \%$ by the substorm process.
\end{abstract}

Keywords. Ionosphere (Electric fields and currents; Midlatitude ionosphere) - Magnetospheric physics (Storms and substorms)

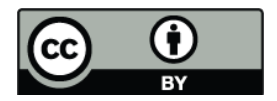

Correspondence to: $\mathrm{H}$. Wang

(h.wang@whu.edu.cn)

\section{Introduction}

The term Subauroral Polarization Streams (SAPS) was introduced by Foster and Burke (2002) referring to rapid westward (sunward) plasma flows located equatorward of the auroral oval predominantly in the dusk and pre-midnight sector (16:00 to 24:00 magnetic local time, MLT). It was the intension of the authors to jointly represent two rather similar phenomena: (1) the polarization jet (PJ) (Galperin et al., 1974) or subauroral ion drift (SAID) (Spiro et al., 1979), which characterize rapid and latitudinally confined plasma flows and (2) plasma flow features with larger latitudinal extent and longer duration, as described e.g. by Yeh et al. (1991). In this study we focus on the SAID-type SAPS. They are one of the interesting and important features at subauroral latitudes, which have been extensively investigated from satellites and radars as well as by magnetospheric simulations (e.g. Spiro et al., 1979; Anderson et al., 1991; Burke et al., 2000; Parkinson et al., 2006; Zheng et al., 2008). In the subsequent parts of the paper the term SAPS will refer exclusively to the narrow plasma jet events.

SAPS are regarded as storm and substorm related phenomena (Spiro et al., 1979; Anderson et al., 1993; Burke et al., 2000). SAPS have been reported to appear during the main phase of a geomagnetic storm (Burke et al., 2000). Karlsson et al. (1998) showed that SAPS get strengthened with enhanced magnetic activity. High convection electric field can inject magnetotail particles equatorward and energize it, thus produce strong R2 FACs (field-aligned currents) flowing into the low conductivity subauroral region. The poleward electric field adjusts to maintain the current continuity in the ionosphere, finally generating SAPS (Anderson et al., 2001). However, whether substorms play an important role or just a secondary role in relation to SAPS occurrence is still under debate (e.g. Daglis and Kozyra, 2002). Spiro et al. (1979) showed that there is a high probability of observing SAPS

Published by Copernicus Publications on behalf of the European Geosciences Union. 
together with a larger AE index. Goldstein et al. (2005) have reported on SAPS events driven by substorms instead of dayside reconnection and discussed their effects on the plasmasphere. Wang et al. (2008) have associated the larger SAPS during relatively low magnetic activity with substorm processes. Karlsson et al. (1998) also noticed that strong subauroral electric fields can be observed during relatively low magnetic activity in winter. The substorm dipolarization process is thought to be able to inject magnetotail particles earthward and to produce sharp increases in ring current particle fluxes, thus produce SAPS (e.g. Ganushkina et al., 2001; Carpenter and Smith, 2001; Goldstein et al., 2005). Parkinson et al. (2006) have predicted that SAPS should occur during every substorm. On the other hand, several modelling studies (McPherron, 1997; Fok et al., 1999) have shown that the enhancement of the cross polar cap potential (CPCP) is the main factor to affect the inner magnetosphere, substorms play a secondary role. The substorm without the enhanced convection can only enhance the cross tail current but has little effect on the inner magnetosphere.

The relationship between SAPS and substorm phase is also controversially discussed. Southwood and Wolf (1978) predicted from their SAPS mechanisms that SAPS should occur shortly after substorm onset when the separation between the ion and electron plasma sheet is the smallest. Burch et al. (1976) found that SAPS can occur during the substorm growth phase. Several observations showed that SAPS can occur during the substorm recovery phase (e.g. Burch et al., 1976; Maynard, 1978; Anderson et al., 1993) when ion and electron plasma sheet have separated from a common inward boundary developed during onset and the whole magnetosphere-ionosphere system has adjusted to a favorable condition for SAPS to occur.

It is necessary to investigate the above mentioned questions with a large data base in order to disclose main controlling factors for SAPS occurrence. The advantage of looking at average properties compared to event studies is that several aspects can be considered simultaneously. We have compiled a list of SAPS events during July 2001 and June 2003 (two years) as identified from DMSP particle measurements in a similar way as Wang et al. (2008). We have selected this period to avoid the super storms in October and November 2003. In this work we will utilize this collection of SAPS events to address the open questions in a statistical approach.

In the sections to follow, we first introduce the method of identification of SAPS events and the data catalogue of the CPCP and substorm onsets used in this study. Then we present the observed occurrence frequency in a month by universal time frame, and discuss the occurrence in the context of the convection electric field, substorm and ionospheric conductivity. We also investigate the time delay between SAPS and substorm onset for different magnetic activity and solar illumination conditions. Finally we have compared our results to previous reports and present our conclusions.

\section{Data sets}

\subsection{DMSP SAPS data}

The DMSP satellites sample polar regions at $\sim 835 \mathrm{~km}$ altitude along orbits of fixed local times. The orbital period is approximately $100 \mathrm{~min}$. One of the considered satellites (F13) has a near dawn-dusk orbit and two (F14, F15) have dayside-nightside MLT orbits. The ion drift velocities in the horizontal and vertical directions perpendicular to the satellite track are derived from the ion drift meter (IDM) data (Rich and Hairston, 1994). The DMSP electron spectrometer (SSJ/4) instruments monitor the energy flux of electrons and ions in the range of $30 \mathrm{eV}$ to $30 \mathrm{keV}$ that precipitate from the Earth's magnetosphere (Hardy et al., 1984). Robinson et al. (1987) have described the relationship between the average electrons energy flux and the height-integrated ionospheric conductivity. Here we make use of this empirical relation for determining the conductivity distribution.

SAPS have been identified similar to the approach described by Wang et al. (2008). It is a clearly identifiable sunward ion flow in the subauroral and premidnight region. A threshold of SAPS velocity greater than $500 \mathrm{~m} \mathrm{~s}^{-1}$ and latitudinal width of $1^{\circ}-2^{\circ}$ (e.g. Spiro et al., 1979; Anderson et al., 2001) is used for selection. The subauroral region is found automatically by computing the auroral Pedersen conductance along the DMSP path and determining the peak conductance, then stepping equatorward until the conductance is reduced to 0.2 times the peak value or $1 \mathrm{~S}$, whichever is smaller. The selected orbits are further visually inspected to fully satisfy the above criteria. The universal time (UT), magnetic local time (MLT), magnetic latitude (MLat) and magnitude of the peak velocities of SAPS are recorded for each event. During July 2001 and June 2003 there are 3663 SAPS events detected in the time sector 15:00-22:00 MLT in the Northern Hemisphere.

\subsection{AMIE CPCP data}

The high latitude ionospheric potential can be described by empirical relationships that relate geomagnetic conditions with solar wind drivers (e.g. Weimer, 1996; Papitashvili and Rich, 2002) and evaluated by data assimilative models that ingest a large amount of observations into a background model (e.g. Kamide et al., 1981; Richmond, 1992). As compared to empirical models, the assimilative model can provide more realistic patterns (e.g. Kihn et al., 2006). Since the AMIE (Assimilative Mapping of Ionospheric Electrodynamics) technique is used extensively in the scientific community, we have employed AMIE to produce the high latitude cross polar cap potential (CPCP) at $1 \mathrm{~min}$ resolution to study its relationship with the SAPS occurrence. The global magnetometer data, the available IMF, solar wind, HPI (Hemispheric Power Index), $F_{10.7}$, and Dst data are used as inputs into the AMIE model (Ridley and Kihn, 2004). A 
comparison of AMIE produced CPCP to the other models has been performed by Ridley (2005), where the advantages of AMIE are stated.

\subsection{Substorm onset data}

Global auroral imagers are considered to be one of the most reliable methods for identifying substorms. A list of substorm onsets based on IMAGE FUV auroal imagers has been compiled by Frey et al. (2004) and Frey and Mende (2007). A detailed description of the instruments used on board the IMAGE spacecraft and how to determine auroral substorm onsets from the FUV instrument can be found in the work of Frey et al. (2004). In the Northern Hemisphere the data covers the period from May 2000 (start of the regular IMAGEFUV operations) through December 2003, while in the south it spans January 2004 to December 2005. The compiled list of substorm onset times and locations covers all seasons quite evenly. Two years of DMSP and IMAGE measurements during the years of 2001 and 2003 have been processed. We have selected altogether 2535 substorm-related SAPS, in which SAPS occur within 0-5 h after the reported substorm onsets.

The reported IMAGE data have been widely used in the space community, however, some suspicions was aroused recently (Weygand et al., 2008). For validation we have further utilized magnetic indices, e.g. AO index (mean value of $\mathrm{AU}$ and AL), as suggested by Benkevitch et al. (2002). The AO index can differentiate substorm process from non-substorm events and is regarded as a better substorm indicator than AL. $\mathrm{AL}$ is related to the westward electrojets and can be driven by both solar wind and substorm related electric fields. AU is related to the eastward electrojets driven by solar wind induced electric fields. During non-substorm time the enhanced convection electric field can lead to an equal increase in both $\mathrm{AU}$ and AL, therefore the AO index remains zero. During substorm time the strong intensification of the westward electrojet in the midnight sector causes a strong increase in the AL index while not so much changes in $\mathrm{AU}$ index, leading to an AO increase. We have compared the reported IMAGE onsets with AO onsets among the selected SAPS events. When the reported auroral breakup time is compared with the AO index onset, we kept the events. After the selection there are 797 events satisfying the above cited criteria and left for the comparative study as described later in sections 3.5-3.6.

We have used the magnetic AO indices to validate IMAGE substorm catalogue. However, one must keep in mind when using magnetic indices that the global distribution of magnetometers that forms the database for deriving $\mathrm{AO}$ indices is rather inhomogeneous. If a substorm occurs within the lacunas there will be a time delay in the time estimate of the onset of the substorm. We have selected substorm events when both IMAGE and AO indices show appropriate signatures. For the time of substorm onsets, however, we rely on the time given by IMAGE. This is not biased by any effect.

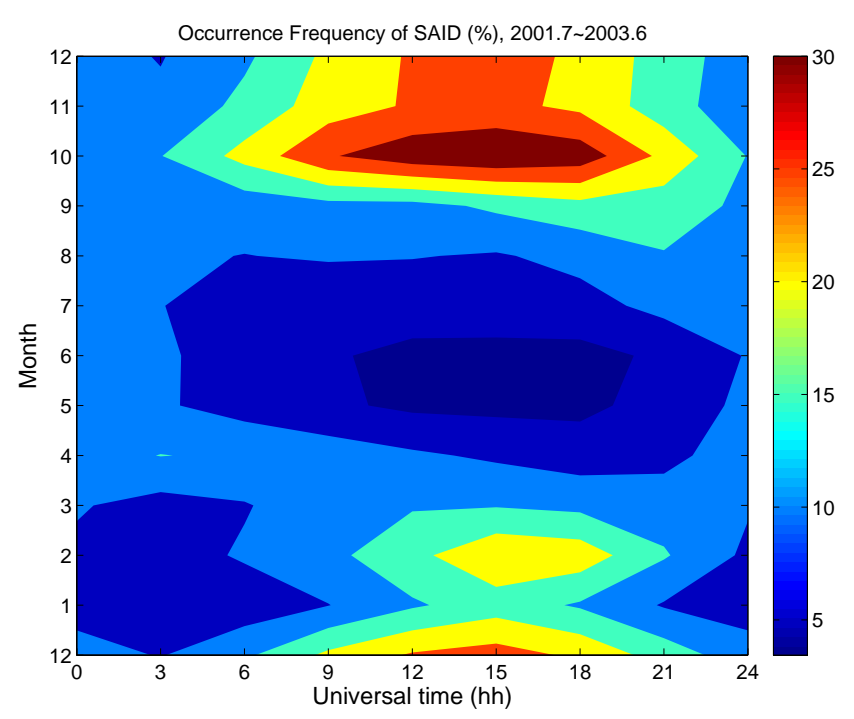

Fig. 1. Contour plot of the seasonal variation of the occurrence of SAID-type SAPS versus UT hours during the observed two years' period. Color code reflects the probability in percent for a SAID to occur during an hour.

\section{Statistical results}

\subsection{Seasonal variation of SAPS occurrence}

In this study we are particularly interested in a possible dependence of the SAPS occurrence rate on the local season. Figure 1 shows the distribution of the occurrence frequency for the two years studied in a month versus universal time diagram. Certain time intervals seem to be more favorable for SAPS to occur than others. For the events considered we determine a linear relationship between longitude and UT, LON $=-16 \times \mathrm{UT}+296^{\circ}$. There is an obvious occurrence peak around October-November centered around 14:00-18:00 UT, which relates to the longitude sector of $10^{\circ}-70^{\circ} \mathrm{E}$. The secondary occurrence peak can be found during December solstice, where we find many SAPS within the time window $12: 00-17: 00 \mathrm{UT}\left(25^{\circ}-105^{\circ} \mathrm{E}\right)$.

The proposed SAPS drivers in the magnetosphere are the convection electric field and the substorm process. Both of them can transport magnetotail particles into the near-Earth region, helping SAPS to develop. In the following we will investigate these parameters separately.

\subsection{Seasonal variation of CPCP}

The convection electric field can be represented by CPCP. Figure 2 shows the occurrence distribution of CPCP $>80 \mathrm{kV}$ in the same format as Fig. 1 during the observed two years' periods. High CPCP predominantly peaks during later Fall due to larger storm events occurring in Fall 2002.

From a comparison between Figs. 1 and 2 we may conclude that the enhanced CPCP can account for the peak SAPS 


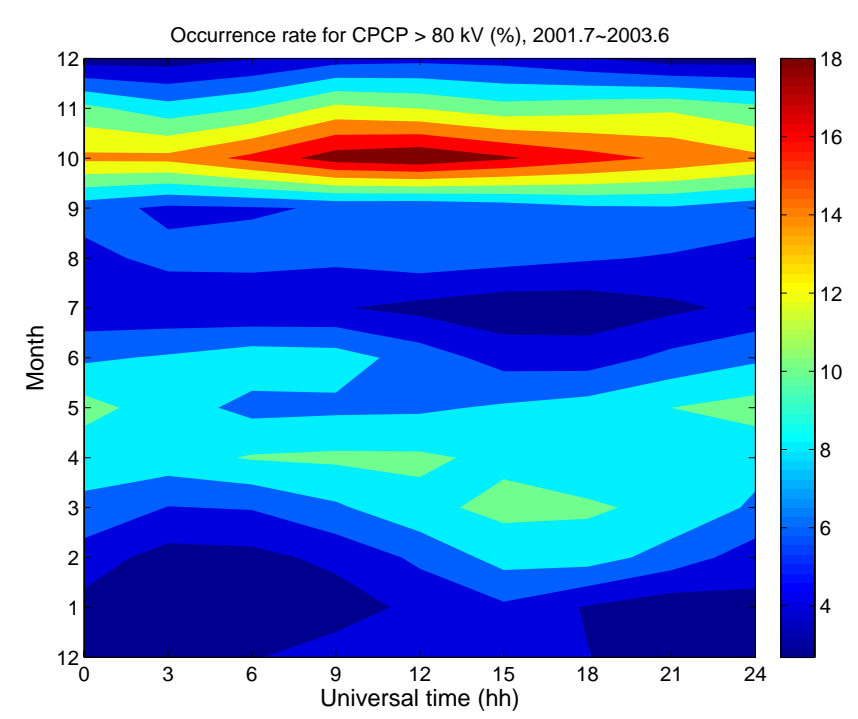

Fig. 2. Same format as Fig. 1, but for occurrence rate of $\mathrm{CPCP}>80 \mathrm{kV}$.

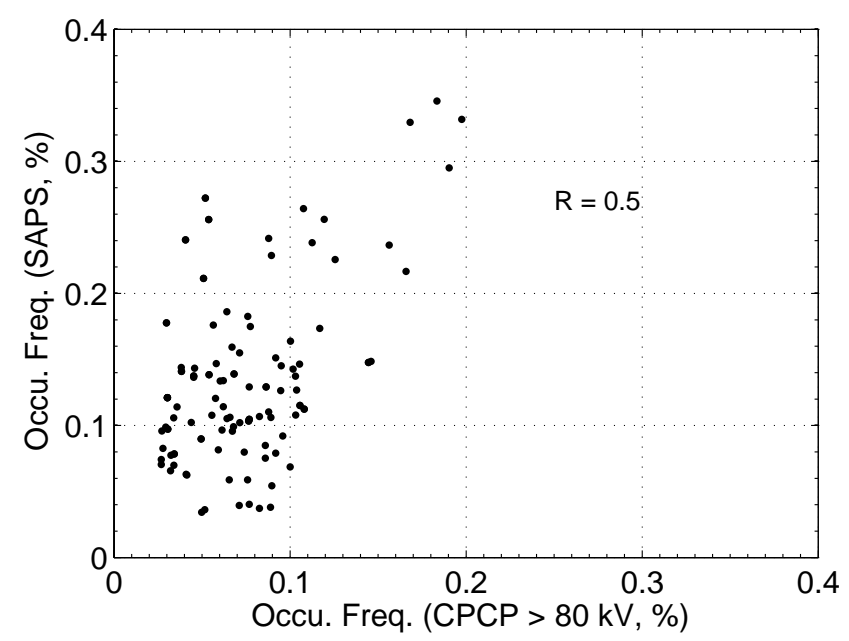

Fig. 3. Correlation analysis of high CPCP versus SAPS occurrence rates.

occurrence rate. According to the generally accepted theory of the SAPS formation (e.g. Anderson et al., 2001), the enhanced convection electric field can inject more ions into the ring current and inner magnetosphere (e.g. Daglis and Kozyra, 2002; Kozyra and Liemohn, 2003; Liemohn and Kozyra, 2003), forming a larger azimuthal pressure gradient. Stronger R2 FACs will be generated by the enhanced misalignment between the large azimuthal pressure gradient and the orientation of the magnetic field flux tube. When larger R2 FACs flow into the ionospheric region of low conductivity in the dusk sector, the electric field has to increase to maintain current continuity. The enhanced poleward electric field is responsible for the development of SAPS. From the above discussion, one can expect that an enhanced CPCP is one of

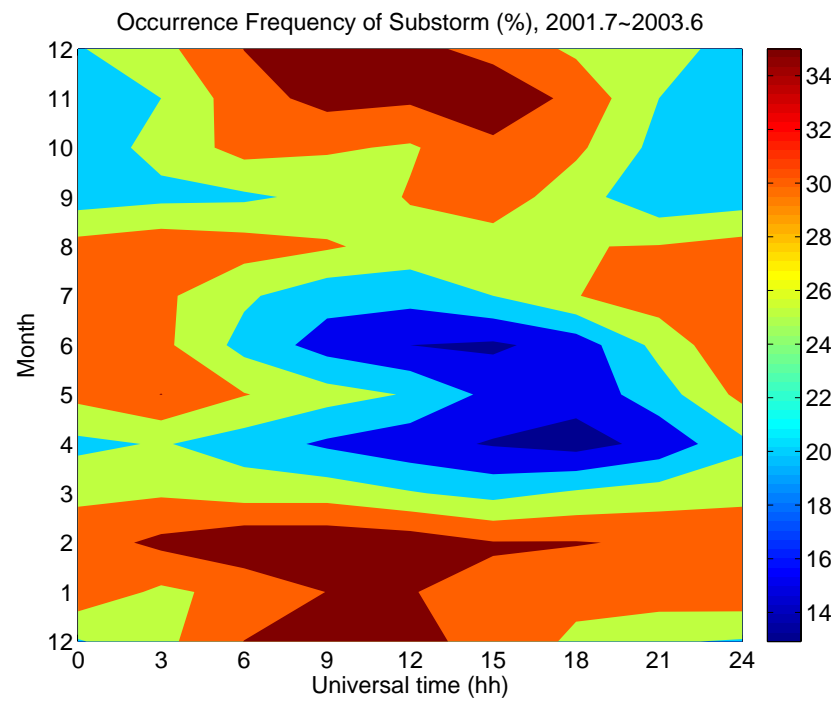

Fig. 4. Same as Fig. 1, but for substorm occurrence rate. The color code shows the probability in percent for a substorm to occur during an hour.

the major drivers for SAPS formation. However, the second enhanced SAPS occurrence during solstices might indicate other driving mechanisms since CPCP is relatively low there.

In order to evaluate the degree of agreement between CPCP and SAPS occurrence, we have performed a correlation analysis of the sequences of two parameters shown in Figs. 1 and 2. The results are shown in Fig. 3. The correlation coefficient we obtained is 0.5 .

\subsection{Seasonal variation of substorm occurrence}

Another possible driver is the substorm process. We have plotted in Fig. 4 similar to the previous work of Wang and Lühr (2007) the seasonal and UT distribution of substorms but restricted to the time interval considered here. It represents the general feature of substorm occurrence comparable to the AO distribution (Benkevitch et al., 2002). Substorms tend to occur during solstice, similar to the SAPS occurrence (see Figs. 1 and 4). Thus, the second occurrence maximum of SAPS can possibly be explained by substorm processes. The direct correlation between substorm and SAPS occurrence is, however, rather poor. There is a time delay of SAPS occurrence with respect to the substorm onset. A cross- correlation analysis has been performed between SAPS selection and onset time. Since SAPS is also affected by CPCP, we have made a cross correlation study between SAPS and substorm occurrence preferably in winter (December, January, February), when CPCP is relative low. As shown in Fig. 5 (left frame) intense SAPS appear about $1.25 \mathrm{~h}$ after a substorm onset. When applying the optimal lag time a correlation ( $R=0.51$ ) between SAPS and substorm is achieved (see Fig. 5 right frame). This result is supporting the role of substorms as drivers for SAPS. 

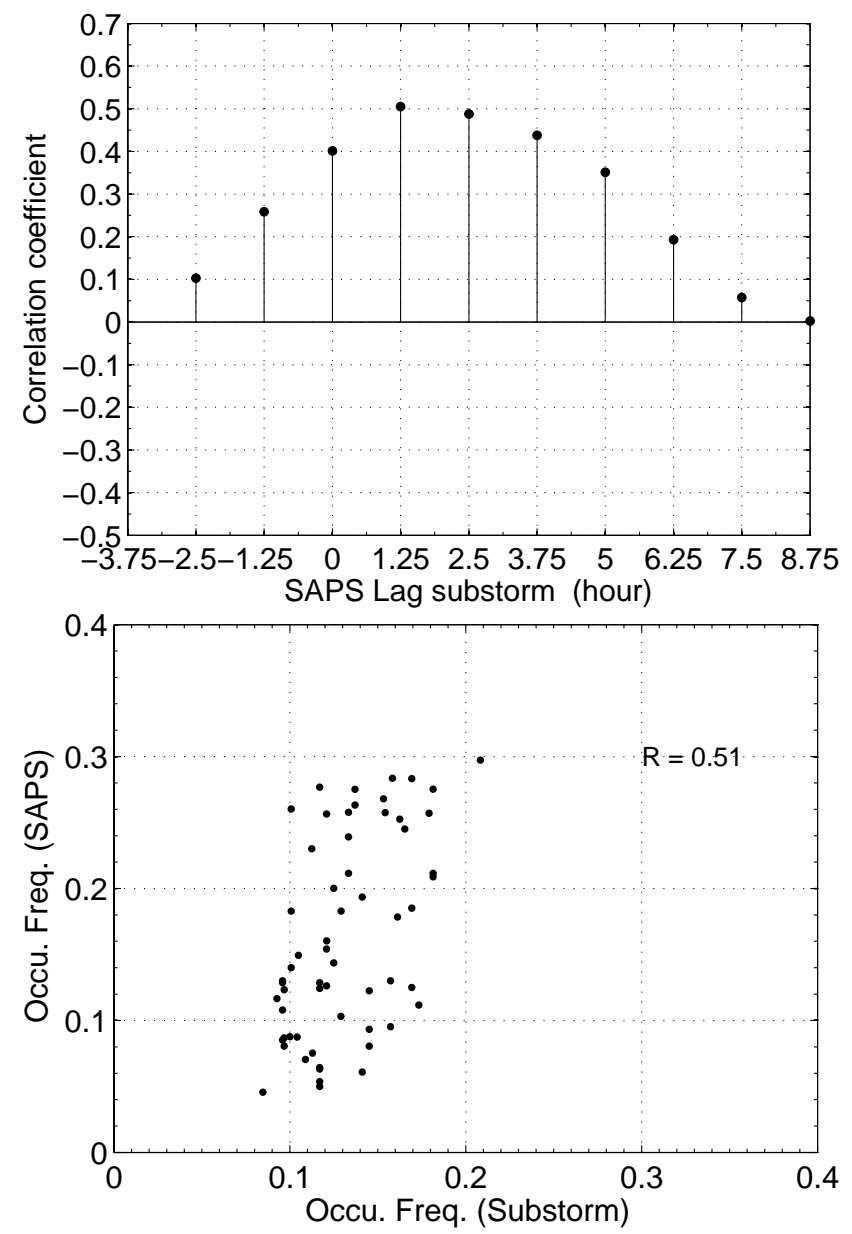

Fig. 5. Correlation between substorm onset and the start of SAPS. Left: cross-correlation coefficients as function of lag time. Right: correlation study of the occurrence of substorm and SAID with $1.25 \mathrm{~h}$ time delay.

\subsection{Seasonal variation of subauroral fluxtube- integrated Pedersen conductivity}

Besides magnetospheric drivers the ionospheric condition is also important for SAPS to occur. We have a look at the ionospheric conductivity caused by solar irradiation since solar illumination is the sole ionization source at subauroral regions. For the estimate of the Pedersen conductivity we made use of the approach by Brekke and Hall (1988). Since the fluxtube on which the onset occurs is connected to both hemispheres, we have plotted in Fig. 6 the expected fluxtubeintegrated Pedersen conductance for a typical SAPS location, $\pm 59^{\circ}$ MLat at 21:00 MLT (Wang et al., 2008). As expected, conductance maxima appear during the two solstices and Fall seasons. When comparing Figs. 1 and 6 we find a clear correlation of high SAPS occurrence rates at times of low conductance, confirming that a relatively low subauroral conductivity is favorable for SAPS to develop.

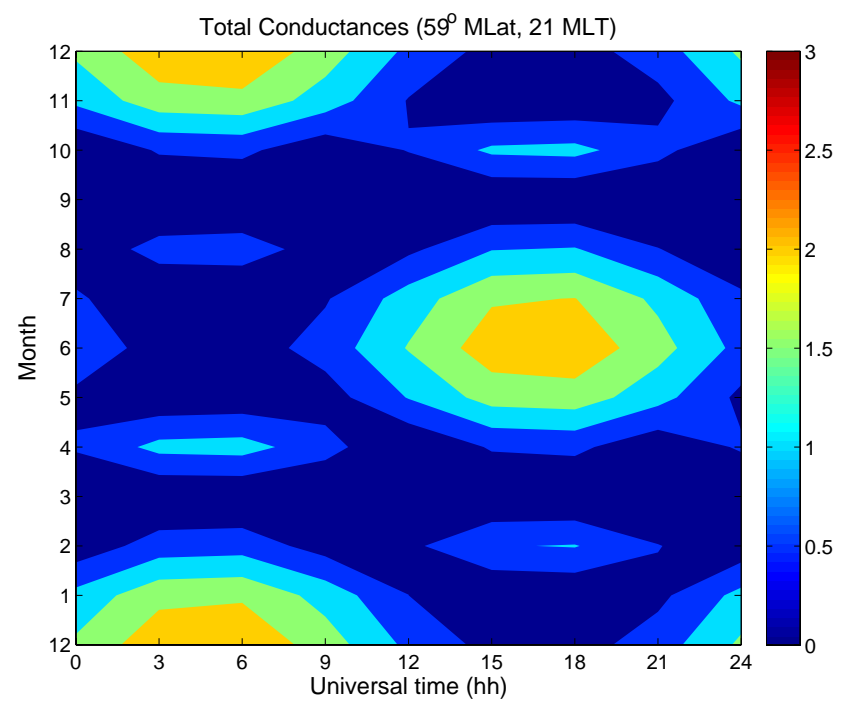

Fig. 6. Variation of fluxtube-integrated Pedersen conductivity, in $\mathrm{S}$, caused by solar irradiation at conjugate footprints, $\pm 59^{\circ}$ MLat, 21:00 MLT.

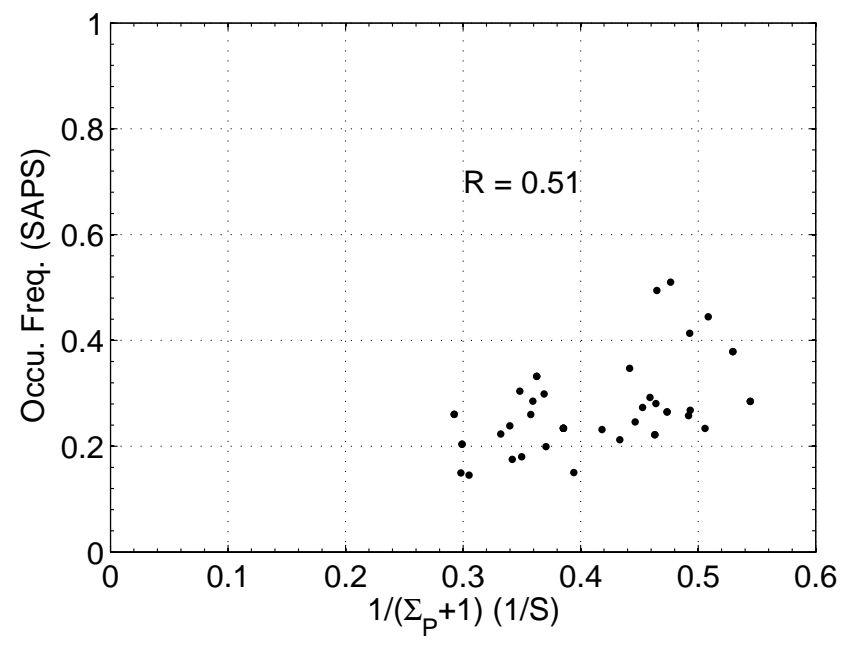

Fig. 7. Correlation analysis of the occurrence of SAPS versus ionospheric impedance.

We show in Fig. 7 the correlation of SAPS occurrence with an estimate of the resistivity, $1 /\left(\Sigma_{P}+1\right)$ (Figs. 1 and 6). A background conductance of $1 \mathrm{~S}$ was included in the calculation. For $1 /\left(\Sigma_{P}+1\right)<0.5$ the correlation coefficient between these two quantities is around 0.5. For low conductances, $\Sigma_{P}<1 S$, the SAPS occurrence rate does not further increase.

\subsection{Magnetic activity effect on time difference between substorm and SAPS}

Figure 8 shows the distribution of the number of events that occur with a certain time delay between substorm onset and 


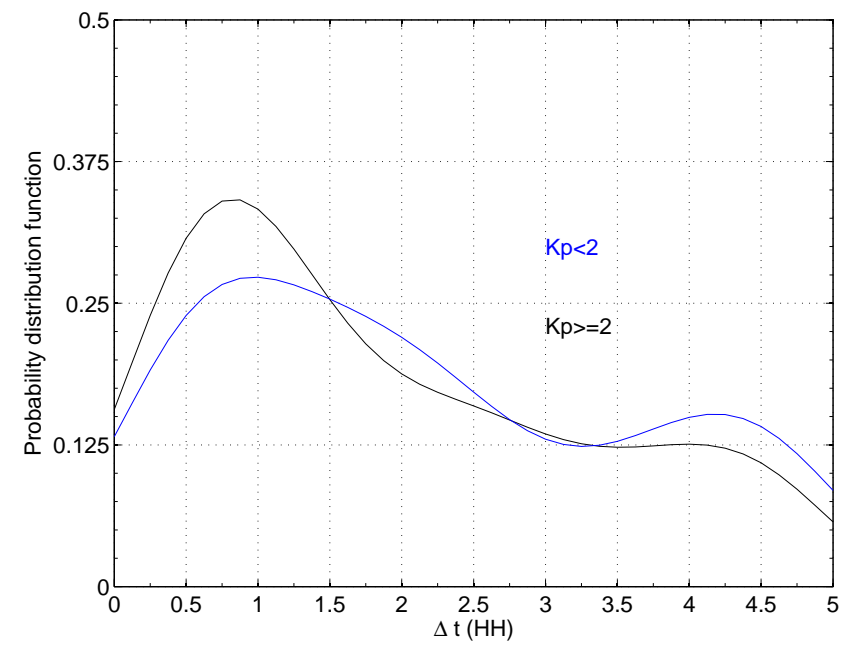

Fig. 8. The probability distribution of the time difference between SAPS and substorm onset for two different levels of geomagnetic activity, $\mathrm{Kp} \geq 2$ (black) and $\mathrm{Kp}<2$ (blue).

the observed SAPS. To consider a possible dependence on geomagnetic activity, we have divided the events into two groups, with $\mathrm{Kp} \geq 2$ for more disturbed periods and $\mathrm{Kp}<2$ for quiet periods. It turns out that the time delay peaks around $1 \mathrm{~h}$ during quiet period and around $0.75 \mathrm{~h}$ during more disturbed periods. The possible reason is that enhanced convection can accelerate the development of SAPS after substorm onsets, thus reduces the waiting time needed for the magnetosphere-ionosphere system to adjust for a SAPS to develop.

\subsection{Conductivity effect on time difference between sub- storm and SAPS}

The ionospheric conductivity might also play a role in the development of SAPS after a substorm. We have subdivided the events into two groups, one from periods of "high rate" and another from "low rate" according to Fig. 4. "High rate" means low fluxtube integrated conductivity and "low rate" means higher conductance (Wang and Lühr, 2007). All events occurring during the months 1 November through 31 March within the time sector 09:00-21:00 UT and the months 1 May through 30 September in the sector 21:0009:00 UT go into the group "high rate". All events occurring during the remaining time are sorted into the "low rate" group (430 events in the high rate and 367 events in the low rate group).

Figure 9 shows the probability density distribution of delay time for these two groups. The time delays seem to peak at the same time, $0.75 \mathrm{~h}$, for both "high rate" and "low rate" groups. The secondary peaks around delays of $4 \mathrm{~h}$ are attributed to a correlation with a previous substorms.

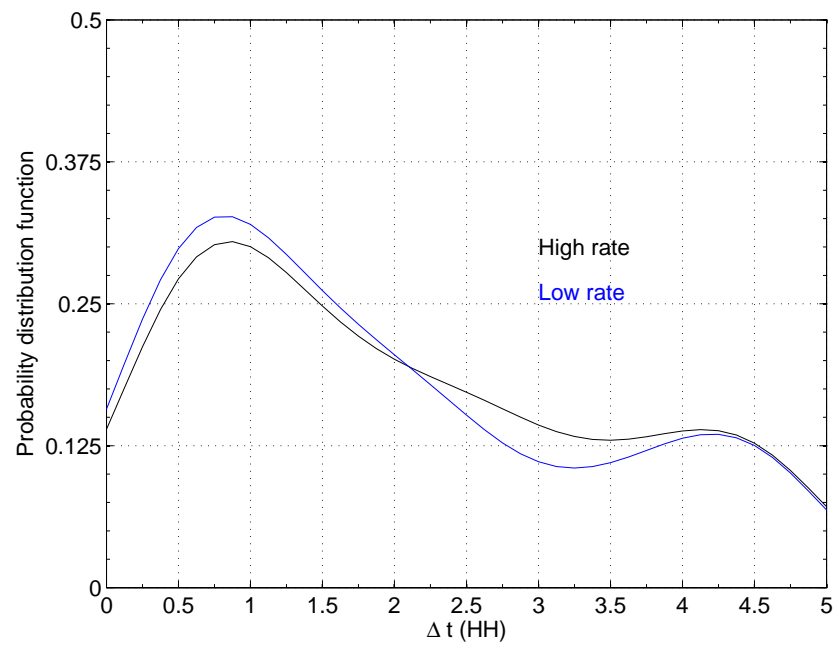

Fig. 9. Same as Fig. 8 except for two groups of "high rate" when solar induced fluxtube integrated conductivity is low (black) and "low rate" when conductance is high (blue).

\section{Discussion}

We have analyzed a large number of subauroral polarization stream events observed by the DMSP satellites. In order to find out possible factors, occurrence rates were compared with other ionospheric phenomena. In the subsequent sections we are going to discuss the relations.

\subsection{Convection electric field effect on SAPS occurrence}

Our study has suggested that the convection electric field may play an important role in association with SAPS. SAPS occurrence rates peak at the same time as the convection electric field maximizes. There is a reasonable correlation between the two parameters. This is consistent with the SAPS mechanism proposed by Anderson et al. (2001) that a high convection electric field can inject and energize particles into the inner magnetosphere. As a consequence the ring current gets enhanced. Stronger R2 FACs flow into the ionosphere, where the low subauroral conductivity requires the poleward electric field to enhance, to maintain the ionospheric current continuity, thus producing fast westward plasma flows (SAPS). Our results are more significant since they are based on a larger number of events. It also confirms previous modelling work (e.g. Fok et al., 1999) that enhanced global convection can generate a credible ring current and that SAPS tend to strengthen with increased geomagnetic activity (Burke et al., 2000).

\subsection{Substorm effect on SAPS occurrence}

It is known that large and rapid changes in the nightside magnetic field during a substorm can induce strong electric fields (e.g. Lopez and Lui, 1990). The induced electric field 
associated with a substorm is believed to be able to transport plasma from the plasma sheet into the inner magnetosphere (e.g. Goldstein et al., 2005). However, other studies thought that substorm induced electric fields have little effect on plasma injections until they are aided by strong convection (e.g. Fok et al., 1999).

Our results suggest that substorms takes over the dominant role in association with SAPS when the CPCP is relatively low (see Figs. 1, 2, 4). There is a secondary SAPS occurrence maximum observed during December solstice due to substorm processes. Our result supports the idea that the substorm induced electric field itself may be capable of transporting enough plasma from the magnetotail into the near Earth region. The rapid sunward motion of geomagnetic field lines during the substorm dipolarization process can inject magnetotail plasma earthward and energize it. Injections will produce sharp increases in ring current particle fluxes, thus produce rapid plasma flow related to substorms (e.g. Ganushkina et al., 2001).

\subsection{Ionospheric effect on SAPS occurrence}

Figure 6 reveals that low ionospheric conductivity helps SAPS to develop when enhanced convection or substorm processes are in progress. High magnetospheric convection or substorm dipolarization can inject and energize ions from the magnetotail into ring current region, producing strong azimuthal pressure gradients (Antonova, 2004). R2 FACs can be generated by the radial magnetic field gradient and the azimuthal ion pressure gradient. R2 FACs in the premidnight sector flow into the ionosphere and close via Pedersen currents through the upward R1 currents, located poleward. When Pedersen currents flow in the low conductivity subauroral region, a somewhat larger poleward electric fields is needed to maintain the current continuity, in turn it produces relatively large westward ion drifts. Thus, it is expected that for low conductivity more often SAPS can develop. We have found that for a Pedersen conductance below $1 \mathrm{~S}\left(1 /\left(\Sigma_{P}+1\right)=0.5\right)$ SAPS occurrence rates tend to stay constant. This matches the general findings of Liemohn et al. (2005) that too low conductance might inhibit the growth of ring current, consequently inhibiting the SAPS development (Liemohn et al., 2005).

In order to quantify the relative roles played by CPCP, substorm, and ionospheric conductivity, we have performed a multi-parameter correlation analysis of quantities shown in Figs. 1, 2, 4, 6.

$\mathrm{Occ}_{\mathrm{SAPS}}^{*}=A \times \mathrm{Occ}_{\mathrm{CPCP}}^{*}+B \times \mathrm{Occ}_{\mathrm{Sub}}^{*}+C \times 1 /\left(\Sigma_{P}+1\right)^{*}(1)$

where ${ }^{*}$ means the normalization operation, e.g. Occ ${ }^{*}=$ $(\mathrm{Occ}-\operatorname{mean}(\mathrm{Occ})) / \max (\mathrm{Occ}) . \quad \mathrm{Occ}_{\mathrm{SAPS}}, \mathrm{Occ}_{\mathrm{Sub}}$, and Occ $_{\text {CPCP }}$ are occurrence rates of SAPS, substorm, and CPCP $\geq 80 \mathrm{kV}$, respectively. We get $A=0.9, B=0.4, C=0.1$. This suggests that CPCP might play the dominant role, substorm a secondary role. The effect of ionospheric conductiv- ity seems to be minor, but is already included in the substorm distribution.

\subsection{Temporal evolution of SAPS}

By using a large data base we have investigated the relationship between SAPS occurrence and substorm onsets. Several SAPS can occur around the substorm onset. We find that during relatively quiet conditions SAPS tend to occur $1 \mathrm{~h}$ after substorm onset, while during disturbed conditions the time delay is reduced to around $45 \mathrm{~min}$. This time delay between SAPS and substorm onset can be explained by the time needed for the separation of electron and ion plasma sheet $(\sim 10 \mathrm{~min})$ and the time needed for the magnetosphere-ionosphere to adjust for SAPS to occur (Anderson et al., 1993). At substorm onset electrons and ions in the plasma sheet are collocated, then gradually separate from each other during the substorm. After that the magnetosphere-ionosphere-thermosphere coupling processes require some time to let SAPS finally occur (for more details we refer to Anderson et al., 1993).

Our results are different from Anderson et al. (1993)'s is in that they found SAPS to occur mostly during the substorm recovery phase with a time delay larger than $30 \mathrm{~min}$. Our results show that SAPS can occur during any phase of substorm and time delay within $0-3 \mathrm{~h}$. The difference might be due to different data base size. They have investigated only 17 substorm related SAPS events, while our data number is around 800 .

In order to resolve the temporal/spatial evolution of SAPS in response to a substorm we performed a superposed epoch analysis applied to DMSP passes occurring around onset. Figure 10 shows in the top row the superposition of crosstrack plasma velocities observed shortly before a substorm. The key location for all events is the magnetic latitude of peak sunward velocity. In the two rows below the velocity distribution observed during the first and second pass after onset is plotted, using the same key latitude as above. The average curves in the fourth row indicate that a substorm does not modify the SAPS velocity distribution very much. When subtracting pre substorm velocities we see that there is a small velocity increase of $5-10 \%$ at the key location, but a stronger effect $15^{\circ}$ in latitude more poleward. The effect of substorm is clearer during magnetically active periods $(\mathrm{Kp}>4)$. For low magnetic activity no substorm effect can be determined at the key location, however, the result may suffer from the too few events, and again some small effect at $15^{\circ}$ poleward. In both cases the latter difference indicates a reduction of anti-sunward plasma velocity at high latitudes after substrom onset.

Another phenomenon shown in Fig. 8 is that strong convection may reduce the delay time. This suggests that globally strong convection helps substorms to inject plasma inward, and it reduces the time of the 

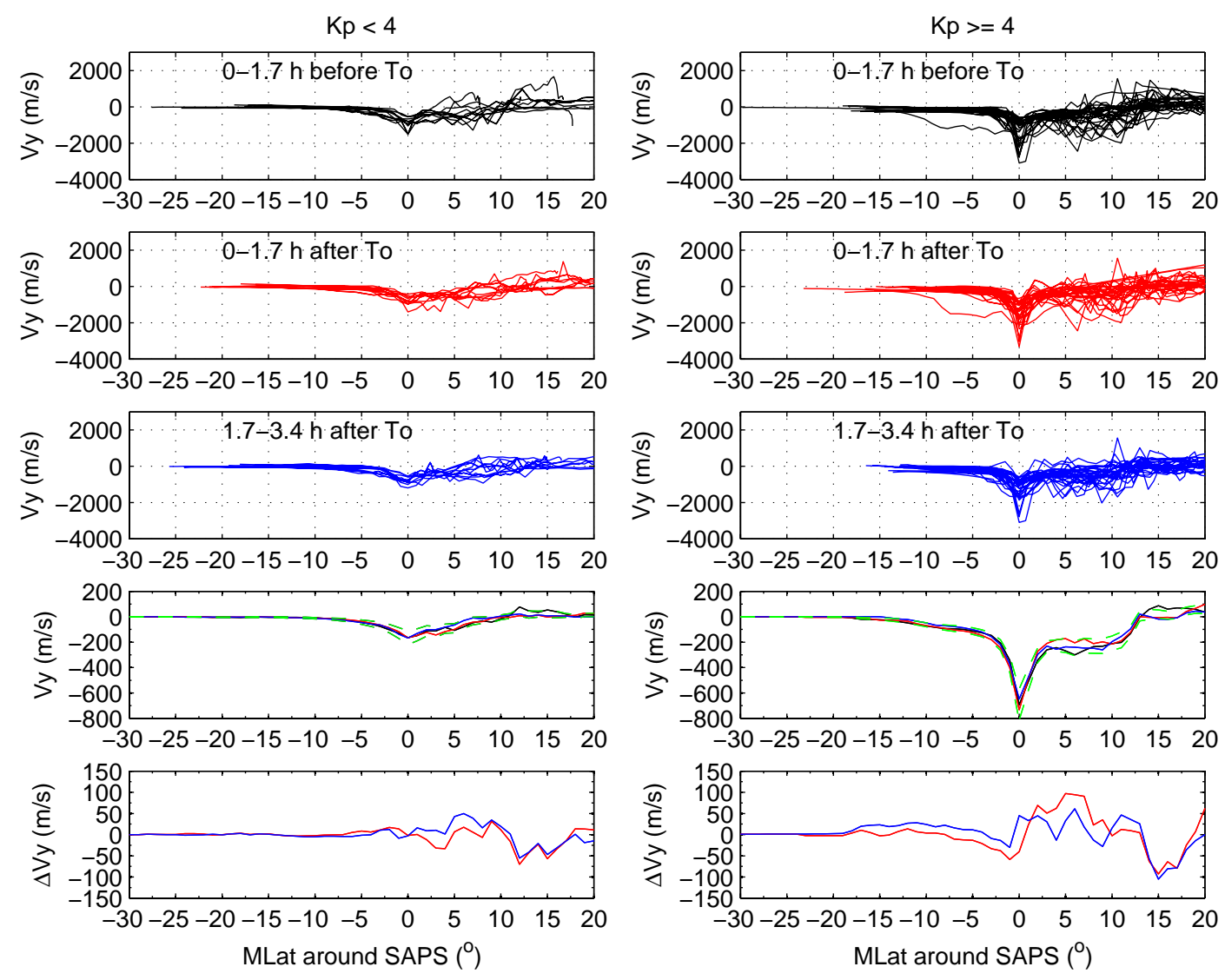

Fig. 10. Stack plots and superposed epoch analysis of the cross track velocity observed by DMSP for Kp $<4$ and Kp $\geq 4$ (top four). The key MLat of " 0 " denotes MLat where SAID peak occurs. Positive denotes eastward velocity. Black lines mark orbits before onset, T0. Red and blue lines denote the successive two orbits after T0. Green dashed lines are mean value of uncertainty for all three curves. Bottom shows the residual velocity after subtraction of the successive two orbits after T0 from the reference before.

magnetosphere-ionosphere-thermosphere system to adjust for SAPS development.

We have to add another point here, DMSP satellites cannot continuously observe SAPS. Due to the $100 \mathrm{~min}$ orbital period of DMSP, we do not know, how much before the detection the SAPS appeared. This will cause a systematical overestimate of the delay time after substorm onset. When considering observations from three DMSP satellites, the bias is expected to be about $15 \mathrm{~min}$. Previous studies on this topis are based on a much smaller data base (Anderson et al., 1993). Parkinson et al. (2006)'s work is based on 98 events detected by radar. We hope that with a larger data base of 797 events uncertainties have been reduced.

\section{Conclusions}

We have investigated the seasonal and diurnal variations of SAPS occurrence rates based on 3663 SAPS events identified from DMSP particle observations in the Northern Hemisphere during July 2001 to June 2003. Their relationship with high latitude convection electric field, substorm, and ionospheric conductivity has been discussed. In addition, the temporal relationship between SAPS and substorm phases have been investigated. Some characteristic results were revealed.

1. Strong convection electric fields play a dominant role in association with the occurrence of SAPS. Peaks in the observed distribution of large convection electric fields coincide with the occurrence maxima of SAPS.

2. Substorms play a secondary role in relation to the occurrence of SAPS. They may account for a second maximum in SAPS occurrence rate during December solstice.

3. A low conductivity is favorable for SAPS to develop. But when the Pedersen conductance is below $1 \mathrm{~S}$ $\left(1 /\left(\Sigma_{P}+1\right)=0.5\right)$ the SAPS occurrence rate tends to saturate.

4. SAPS appear together with substorms. Most probably SAPS occur $60 \mathrm{~min} / 45 \mathrm{~min}$ after substorm onset during quiet/geomagnetic active periods. This may indicate 
that global convection can help substorm to develop SAPS.

5. The substorm process enhances the plasma flow speed of SAPS by about $5-10 \%$ on average during the time span $0-1.7 \mathrm{~h}$ after the onset.

Acknowledgements. We thank the Center for Space Sciences at the University of Texas at Dallas and the US Air Force for providing the DMSP IDM plasma data and the Space Physics Interactive Data Resource (SPIDR) for providing the DMSP SSJ/4 data. The WDC C2 for Geomagnetism at Kyoto are greatly acknowledged for providing the geomagnetic indices data. This work is supported by National Nature Science Foundation of China (No. 40974096), National Basic Research Program of China (973 Program, 2011CB811404), the Scientific Research Foundation for the Returned Overseas Chinese Scholars, State Education Ministry, and the Fundamental Research Funds for the Central Universities.

Topical Editor I. A. Daglis thanks A. Brekke and another anonymous referee for their help in evaluating this paper.

\section{References}

Anderson, P. C., Heelis, R. A., and Hanson, W. B.: The ionospheric signatures of rapid subauroral ion drifts, J. Geophys. Res., 96, 5785-5792, 1991.

Anderson, P. C., Hanson, W. B., Heelis, R. A., Craven, J. D., Baker, D. N., and Frank, L. A.: A proposed production model of rapid subauroral ion drifts and their relationship to substorm evolution, J. Geophys. Res., 98, 6069-6078, 1993.

Anderson, P. C., Carpenter, D. L., Tsuruda, K., Mukai, T., and Rich, F. J.: Multisatellite observations of rapid subauroral ion drifts (SAID), J. Geophys. Res., 106, 29585-29600, doi:10.1029/2001JA000128, 2001.

Antonova, E. E.: Magnetostatic equilibrium and current systems in the Earth's magnetosphere, Adv. Space Res., 33, 752-760, doi:10.1016/S0273-1177(03)00636-7, 2004.

Benkevitch, L. V., Lyatsky, W. B., Koustov, A. V., Sofko, G. J., and Hamza, A. M.: Substorm onset times as derived from geomagnetic indices, Geophys. Res. Lett., 29, 10, doi:10.1029/2001GL014386, 2002.

Brekke, A. and Hall, C.: Auroral ionospheric quiet summer time conductances, Ann. Geophys., 6, 361-375, 1988.

Burch, J. L., Fields, S. A., and Heelis, R. A.: Substorm effects observed in the auroral plasma, Physics of Solar Planetary Environments, edited by: Williams, D. J., AGU, Washington, D.C., 1976.

Burke, W. J., Rubin, A. G., Maynard, N. C., Gentile, L. C., Sultan, P. J., Rich, F. J., de La Beaujardière, O., Huang, C. Y., and Wilson, G. R.: Ionospheric disturbances observed by DMSP at middle to low latitudes during the magnetic storm of June 4-6, 1991, J. Geophys. Res., 105, 18391-18406, doi:10.1029/1999JA000188, 2000.

Carpenter, D. L. and Smith, A. J.: The study of bulk plasma motions and associated electric fields in the plasmasphere by means of whistler-mode signals, J. Atmos. Solar-Terr. Phys., 63, 11171132, 2001

Daglis, I. A. and Kozyra, J. U.: Outstanding issues of ring current dynamics, J. Atmos. Solar-Terr. Phys., 64, 253-264, 2002.
Fok, M. C., Moore, T. E., and Delcourt, D. C.: Modeling of inner plasma sheet and ring current during substorms, J. Geophys. Res., 104, 14557-14569, 1999.

Foster, J. C. and Burke, W. J.: SAPS: A new categorization for sub-auroral electric fields, EOS Transactions, 83, 393, doi:10.1029/2002EO000289, 2002.

Frey, H. U. and Mende, S. B.: Substorm onset observations by IMAGE-FUV: 2003-2005, in: Proceedings of the Eighth International Conference on Substorms, edited by: Syrjäsuo, M. and Donovan, E., p. 215, Univ. of Calgary, Alberta, Canada, 2007.

Frey, H. U., Mende, S. B., Angelopoulos, V., and Donovan, E. F.: Substorm onset observations by IMAGE-FUV, J. Geophys. Res., 109, A10304, doi:10.1029/2004JA010607, 2004.

Galperin, Y., Ponomarev, V. N., and Zosimova, A. G.: Plasma convection in the polar ionosphere, Ann. Geophys., 30, 1-7, 1974.

Ganushkina, N. Y., Pulkkinen, T. I., Bashkirov, V. F., Baker, D. N., and Li, X.: Formation of intense nose structures, Geophys. Res. Lett., 28, 491-494, doi:10.1029/2000GL011955, 2001.

Goldstein, J., Burch, J. L., Sandel, B. R., Mende, S. B., C:son Brandt, P., and Hairston, M. R.: Coupled response of the inner magnetosphere and ionosphere on 17 April 2002, J. Geophys. Res., 110, 205, doi:10.1029/2004JA010712, 2005.

Hardy, D. A., Schmitt, L. K., Gussenhoven, M. S., Marshall, F. J., and Yeh, H. C.: Precipitating electron and ion detectors (SSJ/4) for the block 5D/Flights 6-10 DMSP (Defense Meteorological Satellite Program) satellites: Calibration and data presentation, Rep. AFGL-TR-84-0314, Air Force Geophys. Lab., Air Force Base, MA, 1984.

Kamide, Y., Richmond, A. D., and Matsushita, S.: Estimation of ionospheric electric fields, ionospheric currents, and fieldaligned currents from ground magnetic records, J. Geophys. Res., 86, 801-813, 1981.

Karlsson, T., Marklund, G. T., and Blomberg, L. G.: Subauroral electric fields observed by the Freja satellite: A statistical study, J. Geophys. Res., 103, 4327-4341, 1998.

Kihn, E. A., Redmon, R., Ridley, A. J., and Hairston, M. R.: A statistical comparison of the AMIE derived and DMSP-SSIES observed high-latitude ionospheric electric field, J. Geophys. Res., 111, A08303, doi:10.1029/2005JA011310, 2006.

Kozyra, J. U. and Liemohn, M. W.: Ring Current Energy Input and Decay, Space Sci. Rev., 109, 105-131, doi:10.1023/B:SPAC.0000007516.10433.ad, 2003.

Liemohn, M. W. and Kozyra, J. U.: Lognormal form of the ring current energy content, J. Atmos. Solar-Terr. Phys., 65, 871-886, doi:10.1016/S1364-6826(03)00088-9, 2003.

Liemohn, M. W., Ridley, A. J., Brandt, P. C., Gallagher, D. L., Kozyra, J. U., Ober, D. M., Mitchell, D. G., Roelof, E. C., and DeMajistre, R.: Parametric analysis of nightside conductance effects on inner magnetospheric dynamics for the 17 April 2002 storm, J. Geophys. Res., 110, S22, doi:10.1029/2005JA011109, 2005.

Lopez, R. E. and Lui, A. T. Y.: A multisatellite case study of the expansion of a substorm current wedge in the near-Earth magnetotail, J. Geophys. Res., 95, 8009-8017, 1990.

Maynard, N. C.: On large poleward-directed electric fields at subauroral latitudes, J. Geophys. Res., 5, 7, 1978.

McPherron, R. L.: The role of substorms in the generation of magnetic storms, in: Magnetic storms, Geophys. Monogr. Ser., edited by: Tsurutani, B. T., Gonzalez, W. D., Kamide, Y., and Arballo, 
J. K., 1997.

Papitashvili, V. O. and Rich, F. J.: High-latitude ionospheric convection models derived from Defense Meteorological Satellite Program ion drift observations and parameterized by the interplanetary magnetic field strength and direction, J. Geophys. Res., 107, 1198, doi:10.1029/2001JA000264, 2002.

Parkinson, M. L., Dyson, P. L., and Pinnock, M.: On the occurrence of auroral westward flow channels and substorm phase, Adv. Space Res., 38, 1755-1762, 2006.

Rich, F. J. and Hairston, M.: Large-scale convection patterns observed by DMSP, J. Geophys. Res., 99, 3827-3844, 1994.

Richmond, A. D.: Assimilative mapping of ionospheric electrodynamics, Adv. Space Res., 12, 59-68, doi:10.1016/02731177(92)90040-5, 1992.

Ridley, A. J.: A new formulation for the ionospheric cross polar cap potential including saturation effects, Ann. Geophys., 23, 35333547, doi:10.5194/angeo-23-3533-2005, 2005.

Ridley, A. J. and Kihn, E. A.: Polar cap index comparisons with AMIE cross polar cap potential, electric field, and polar cap area, Geophys. Res. Lett., 31, 801, doi:10.1029/2003GL019113, 2004.

Robinson, R. M., Vondrak, R. R., Miller, K., Dabbs, T., and Hardy, D. A.: On calculating ionospheric conductances from the flux and energy of precipitating electrons, J. Geophys. Res., 92, 2565-2569, 1987.

Southwood, D. J. and Wolf, R. A.: An assessment of the role of precipitation in magnetospheric convection, J. Geophys. Res., 83, 5227-5232, 1978.
Spiro, R. W., Heelis, R. H., and Hanson, W. B.: Rapid sub-auroral ion drifts observed by Atmospheric Explorer C, Geophys. Res. Lett., 6, 657-660, 1979.

Wang, H. and Lühr: Seasonal-longitudinal variation of substorm occurrence frequency: Evidence for ionospheric control, Geophys. Res. Lett., 34, L07104, doi:10.1029/2007GL029423, 2007.

Wang, H., Ridley, A. J., Lühr, H., Liemohn, M. W., and Ma, S. Y.: Statistical study of the subauroral polarization stream: Its dependence on the cross-polar cap potential and subauroral conductance, J. Geophys. Res., 113, 12311, doi:10.1029/2008JA013529, 2008.

Weimer, D. R.: A flexible, IMF dependent model of high-latitude electric potentials having "space weather" applications, Geophys. Res. Lett., 23, 2549-2552, doi:10.1029/96GL02255, 1996.

Weygand, J. M., McPherron, R. L., Frey, H. U., Amm, O., Kauristie, K., Viljanen, A., and Koistinen, A.: Relation of substorm onset to Harang discontinuity, J. Geophys. Res., 113, A04213, doi:10.1029/2007JA012537, 2008.

Yeh, H.-C., Foster, J. C., Rich, F. J., and Swider, W.: Storm time electric field penetration observed at mid-latitude, J. Geophys. Res., 96, 5707-5721, 1991.

Zheng, Y., Brandt, P. C., Lui, A. T., and Fok, M. C.: On ionospheric trough conductance and subauroral polarization streams: simulation results, J. Geophys. Res., 113, 209, doi:10.1029/2007JA012532, 2008. 